\title{
Correction to: How can primary care practitioners address substance use by adolescents? A position paper of the EUROPEAN academy of PAEDIATRICS
}

\author{
Pierre-André Michaud $^{1} \cdot$ Richard Bélanger $^{2} \cdot$ Artur Mazur $^{3} \cdot$ Adamos Hadjipanayis $^{4} \cdot$ Anne-Emmanuelle Ambresin $^{5}$
}

Published online: 18 May 2020

(C) Springer-Verlag GmbH Germany, part of Springer Nature 2020

\section{Correction to: European Journal of Pediatrics} https://doi.org/10.1007/s00431-020-03596-6

The authors of the published version of this article inadvertently omitted the table note of the Table 2 under the Appendix section. The complete Table 2 is shown as follows:

The online version of the original article can be found at https:/doi.org/ 10.1007/s00431-020-03596-6

Pierre-André Michaud

pierre-andre.michaud@chuv.ch

Richard Bélanger

ricbelanger@hotmail.com

Artur Mazur

drmazur@poczta.onet.pl

Adamos Hadjipanayis

Cyprusadamos@paidiatros.com

Anne-Emmanuelle Ambresin

Anne-Emmanuelle.Ambresin@chuv.ch
University hospital, Pierre-André Michaud Sauge, 15 1030 Bussigny, Switzerland

2 Département de pédiatrie, Faculté de médecine, Université Laval, QC, Québec G1V 0A6, Canada

3 Faculty of Medicine, University of Rzeszów, Rzeszów, Poland

4 Medical School, European University of Cyprus, Nicosia, Diogenis Str 6, 2404 Nicosia, CY, Cyprus

5 University hospital, Lausanne, Lausanne, Switzerland 
Appendix

Table 2 The CRAFFT+N screening tool (with permission [28])

\title{
The CRAFFT+N Questionnaire
}

\author{
To be completed by patient
}

Please answer all questions honestly; your answers will be kept confidential.

During the PAST 12 MONTHS, on how many days did you:

1. Drink more than a few sips of beer, wine, or any drink containing alcohol? Put "0" if none.

2. Use any marijuana (weed, oil, or hash by smoking, vaping, or in food) or "synthetic marijuana" (like "K2," "Spice")? Put "0" if none.

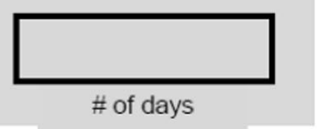

3. Use anything else to get high (like other illegal drugs, prescription or over-the-counter medications, and things that you sniff, huff, or vape)? Put " 0 " if none.

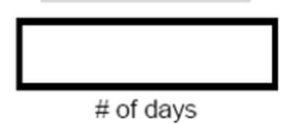

\# of days

4. Use any tobacco or nicotine products (for example, cigarettes, e-cigarettes, hookahs or smokeless tobacco)? Put " 0 " if none.
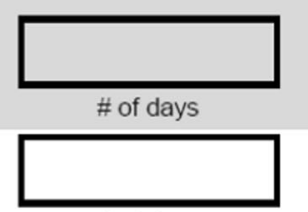

\# of days

READ THESE INSTRUCTIONS BEFORE CONTINUING:

- If you put "0" in ALL of the boxes above, ANSWER QUESTION 5, THEN STOP.

- If you put "1" or higher in ANY of the boxes above, ANSWER QUESTIONS 5-10.

\section{No Yes}

5. Have you ever ridden in a CAR driven by someone (including yourself) who was "high" or had been using alcohol or drugs?

6. Do you ever use alcohol or drugs to RELAX, feel better about yourself, or fit in?

7. Do you ever use alcohol or drugs while you are by yourself, or ALONE?

8. Do you ever FORGET things you did while using alcohol or drugs?

9. Do your FAMILY or FRIENDS ever tell you that you should cut down on your drinking or drug use?

10. Have you ever gotten into TROUBLE while you were using alcohol or drugs?

(C) John R. Knight, MD, Boston Children's Hospital, 2018

All rights reserved. Reproduced with permission

For more information, contact crafft@ childrens.harvard.ed

Publisher's note Springer Nature remains neutral with regard to jurisdictional claims in published maps and institutional affiliations. 